\title{
So You Want to Create a Student Research Journal? How to Craft a Journal Based on Peer Learning
}

Kimberly Cowell-Meyers, American University

Ben Mainwaring, YouGov

Sean Dugdale, 10o,ooo Strong Foundation

Carly Kinney, SimpsonScarborough

Brian Hanson, US Department ofJustice

ABSTRACT Although many university educators and administrators seek to promote student research, opportunities to do so often are rare or costly. This case study of the undergraduate academic journal Clocks\&Clouds provides a clear model for reaping the rewards of this high-impact educational experience based on peer learning.

The goal of this article is to institutionalize knowledge by reviewing Clocks\&Clouds, American University's undergraduate research journal in political science, international relations, and public policy. Input from three successive teams of student leaders, as well as interviews with administrators and faculty members at American University, suggests a method for creating a journal and "lessons learned" that can be applied at other institutions. The article builds on the research of Mariani et al. (2013), which considered various organizational strategies that political science departments use to structure undergraduate student publications. It highlights three facets of a model undergraduate journal in political science: organizational structures, peer-review process, and funding and resources. The purpose of this study was to encourage other undergraduate programs in political science to create student research publications and expand the reach of this high-impact educational practice.

Kimberly Cowell-Meyers is on the faculty of the American University government department. Her work focuses on the politics of gender, religion, and identity, including the role of gender in institutions such as legislatures and political parties. She can be reached at kcowell@american.edu.

Ben Mainwaring is a quantitative analyst at YouGov. He holds an MSc in public opinion research from the University of Essex (where he was a Fulbright Scholar) and a BA from American University. He was the founding editor-in-chief of Clocks\&Clouds in 2012. He can be reached at mainwaringb@gmail.com.

Sean Dugdale is a project manager at the 10o,ooo Strong Foundation, which seeks to strengthen the US-China strategic relationship through student exchange. He graduated from American University with BA degrees in international relations and East Asian studies. He was editor-in-chief of Clocks\&Clouds in 2013-14. He can be reached at seandugdale@gmail.com. Carly Kinney graduated from American University with a BA in statistics and political science. She currently works as a data analyst at SimpsonScarborough, where she analyzes survey research for colleges and universities nationwide. She was the Clocks\&Clouds editor-in-chief in 2012-13. She can be reached at carly.1.kinney@gmail.com.

Brian Hanson is an analyst at the US Department of Justice. He received his BA in political science from American University and his MPA from George Washington University. He was the founding managing editor of Clocks\&Clouds in 2012. He can be reached at brianhanson15@gmail.com.

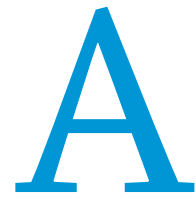

lthough many university educators and administrators seek to promote student research, opportunities to do so often are rare or costly. Results from the National Survey of Student Engagement educational practice that fosters knowledge and engagement and provides opportunities for integrative and applied learning (Kuh 2008). Dedicated programs in undergraduate research can significantly benefit students, faculty, and universities more broadly, according to Osborn and Karukstis (2009), who argue that the experience for undergraduates is potentially "transformational." Yet, even talented undergraduates require relatively time-intensive mentoring to learn about and conduct the research process. How can a school expand the opportunities for meaningful student engagement in research without increasing the burden on faculty and staff? This case study of the undergraduate academic journal Clocks $\mathcal{E}$ Clouds provides a clear model for reaping the rewards of this high-impact educational experience based on peer learning. 
Giving students the opportunity to publish their scholarship can extend the benefits of undergraduate research and work as a powerful pedagogical tool (Smith et al. 2009), which enables them to build research skills through guided peer learning. Submissions to or publication in undergraduate journals helps students to learn about the research process (Bauer et al. 2009; Smith et al. 2009; Watcke and Winterfield 1979); boosts their confidence and interest in conducting research (Bauer et al. 2009; Russell, Hancock, and McCullough 2007); improves their writing skills (Bauer et al. 2009); and produces higher-quality research (Charlesworth and Foster 1996). Whereas most scholarship on undergraduate research journals focuses on the natural sciences, research by Mariani et al. (2013) affirms that these journals also promote student engagement in political science research, provide models for success, and encourage student-faculty interaction.

Although creating an undergraduate student research journal can yield dividends, it also can be daunting because it depends on a frustrating process of trial and error. Perhaps as a result, only were chosen by faculty (rather than by student members of the organization) and faculty advisors were involved in operating the journal. Most student editorial teams did not earn academic credit or compensation for their work; however, about a third did receive credit. Journal resources also varied: most were supported financially by the university or program; many also received funding from student organizations. Finally, editing responsibilities were divided between scenarios in which students did all or most of the work and those in which the work was shared with or accomplished by faculty (Mariani et al. 2013). The following sections describe the model used by Clocks\&Clouds to address these issues.

\section{ORGANIZATIONAL OVERVIEW OF CLOCKS\&CLOUDS}

In 2011, one faculty member (Assistant Professor Kimberly Cowell-Meyers) and one associate dean (Meg Weekes) in the School of Public Affairs (SPA) at American University decided to create a student journal to give a wider audience to undergraduate research papers. The vision was for an almost entirely student-led

\section{These journals also promote student engagement in political science research, provide models for success, and encourage student-faculty interaction.}

about 20 political science programs in the United States currently have active journals, ${ }^{1}$ and there is little institutional knowledge about managing them. ${ }^{2}$ Both faculty and students-including those with substantial leadership experience-may encounter a steep learning curve in managing an undergraduate journal.

The goal of this article is to institutionalize knowledge by reviewing an emerging undergraduate research journal. Specifically, we highlight operating procedures and decisions made by Clocks\&Clouds, American University's undergraduate research journal in political science, international relations, and public policy. Input from three successive teams of student leaders-in addition to interviews with administrators and faculty members at American University—suggests a method for creating a journal and "lessons learned" that can be applied at other institutions. The article builds on research by Mariani et al. (2013), which considered various organizational strategies used by political science departments to structure undergraduate student publications. The article examines one model of success, which may be particularly appealing to other departments and programs because it does not require curricular reorganization or significant funding commitments and it depends primarily on peer learning.

Using Clocks\&Clouds as a case study, this article highlights three facets of a model undergraduate journal in political science. Following a brief overview of ClocksEClouds and its relationship to the organizational options discussed by Mariani et al. (2013), details of its organizational structures are discussed. We describe the way in which the journal adapts a peer-review process to undergraduates and how it trains reviewers to participate in the journal, followed by a discussion of the journal's funding and resources. The article concludes with key challenges that many undergraduate research journals are likely to encounter and provides potential responses to them.

\section{STRUCTURAL AND ORGANIZATIONAL OPTIONS}

As Mariani et al. (2013) discerned in their survey of undergraduate journal editors, student journals in political science vary considerably in structure. For example, a majority of student leaders journal. For the first round of student leaders, the faculty member tapped two senior honors students in political science from previous classes. Using faculty recommendations and referrals, those two then recruited a staff of 10 and a reviewer team of approximately 25 students. The first issue of the journal was published in the spring of 2012. The School of International Service (SIS) joined the effort in early 2012 and contributed staff, reviewers, and submissions before the launch of the first issue, thereby expanding the journal's reach. ${ }^{3}$

The journal has made a significant contribution to the campus community since its founding. It strengthens the undergraduate research curriculum in political science and international affairs by drawing submissions and reviewers from the required research-methods and capstone courses. The journal provides an opportunity for students to go beyond research conducted in the classroom, to refine the skills learned, to engage in writing as an iterative process, and to participate in the process of developing high-quality research suitable for publication (Stallings 2014). The process encourages students to pursue research opportunities in subsequent academic years.

To date, Clocks\&Clouds has published two issues per academic year with five to seven peer-reviewed articles in each issue. It has sustained a reviewer and staff team of 30 students for 3 academic years and has received approximately 100 submissions for the 4 issues, which is an acceptance rate of $20 \%$. Journal editors have received multiple university awards for their service and scholarship. Published both in print and online, the journal currently is used for admissions and recruitment purposes and constitutes a point of pride for the university.

\section{STRUCTURE}

Drawing from models of professional peer-reviewed journals, student leaders and faculty advisors chose to structure the organization with an editorial staff including an editor-inchief (EIC) and a managing editor (ME), as well as a marketing editor, a production editor, and a team of assistant editors for each position. 
The organization is overseen by a governing board composed of faculty advisors from the SPA and the SIS, two additional faculty members, two undergraduate student-council members, and the EIC and ME. Based on published and privately solicited requests for applications, the governing board selects the successor EIC and ME from a list of candidates nominated by the current EIC and ME and approves all changes to the organization's by-laws and constitution. Faculty advisors meet regularly with the senior staff and participate in training reviewers and staff. Although other members of the governing board have only minor organizational roles, their participation is important because it grounds the journal in multiple constituencies, thereby legitimating the journal on campus.

This structure addresses three common and key concerns related to student organizations. First, the journal format is a hybrid of student activity and academic programming. Although it is intended to be a student organization, the journal has the potential to impact the reputation and public image of the two academic programs that it represents, which formalizes the faculty's role. The faculty advisor role in recruiting and training reviewers and staff is significant. The governing board chooses the leadership team each year, thereby ensuring continuity of vision and professional oversight. Because the journal operates between traditional academics and social activities, it is not incorporated into the student activities structure on campus. Rather, it operates with recognition from university offices based on the organization's affiliation with academic departments.

Second, senior staff members (i.e., the EIC and the ME) are eligible for three credit hours in independent study with the faculty advisors. This element of the structure was created to bridge the student activity/academic distinction and to acknowledge the learning experience from participating in the journal. It also was added to allay concerns about attracting top talent, given that the inaugural leadership spent 10 to 15 hours a week in journal service during the first semester. By streamlining the review process and staggering journal deadlines and review cycles, successive staff succeeded in reducing this commitment to 5 to 10 hours a week. The option

\section{REVIEW PROCESS}

Using professional peer-reviewed journals as a model, the leadership chose to institute a double-blind review process. The journal solicits submissions from all current students as well as alumni who submit their undergraduate work in the year following graduation (this captures senior theses and other final coursework). These papers are not necessarily related to a course, although most emerge from the required methods and senior honors capstone courses. Submissions can be from any field in the SPA and the SIS, including American politics, comparative politics, international relations, legal studies, conflict resolution, international development, US foreign policy, international communication, public policy, public administration, and political theory. Clocks $\mathcal{E}$ Clouds does not publish literature reviews, policy briefings, memos, or essays; therefore, all submissions should be an original contribution to the field of study. Submissions may use any accepted methodology-quantitative or qualitative-but they may not have already appeared in print or be under consideration in other venues. These submissions are solicited using every available means, including writing and speaking to faculty who teach upper-level courses, sending e-mails to all majors in the two schools, and posting notices around campus and on Facebook. The journal also sponsors an information table at undergraduate research conferences and many student gatherings.

All submissions are screened initially by the EIC and then sent to three students with academic training in the subject matter. ${ }^{4}$ They have approximately two weeks to review each article and provide feedback to an assistant managing editor (AME). ${ }^{5}$ AMEs integrate the comments and prepare recommendations about the articles to present to the entire senior staff in a workshop session. Together, the team decides to accept the article, invite revisions, or reject it. ${ }^{6}$ Authors receive a letter that explains the decision and notes the recommended revisions. 7 They are given an additional four weeks to revise and resubmit their article; resubmissions then are returned to the original reviewers for their feedback. Printing is deferred until the following semester, which maximizes the time needed for reviewing and editing. After three years of attempting to finish the work involved in copyediting and

\section{Faculty advisors do not have a significant role in reviewing or editing submissions; however, they are integral to developing and training a team of reviewers.}

of academic credit acknowledges the enormous amount of work that operating the journal requires, and it also professionalizes the journal.

Third, because sustainability of the organization is a key concern for all undergraduate entities, this structure enables the integration and recruitment of underclass students into the leadership team as reviewers and assistant editors. Participation in these junior roles trains and grooms students for the more senior staff positions. Leaders also provide mentorship opportunities to interested underclass students, such as attending meetings and drafting or reviewing policy documents. These opportunities have been strengthened by the addition of "scalable involvement," such as through self-selected journal committees, which allow students to become more involved in the specific aspect(s) of the journal that interests them (e.g., review, author relations, institutionalization, and external relations). design within one semester, the journal has moved to publishing one volume every April that includes work solicited and reviewed in the spring and fall cycles of the previous calendar year. ${ }^{8}$

Faculty advisors do not have a significant role in reviewing or editing submissions; however, they are integral to developing and training a team of reviewers. Clocks $\mathcal{E}$ Clouds requires that all reviewers have completed the required methods courses in their respective programs, usually taken in their sophomore year. This ensures that reviewers have a basic level of training in literature review, research design, and scholarly practice. However, all new reviewers must undergo a training process, which involves work-shopping papers with the faculty advisors and the editorial team, dissecting sections of previous papers, and comparing their own evaluations with those of past staff members. Reviewers are given examples from each category of evaluation and coached on what type of feedback is productive. 
They are trained to understand their role as a research and writing coach, not as a judge.

Third, the feedback solicited from reviewers is structured through a rubric that was developed in consultation between the editorial staff and the faculty advisors. Reviewers are prompted to rate and provide comments on the submission in distinct categories: contribution to existing knowledge, use of theory and quality of hypotheses, appropriateness of research design, and author's execution of the design. Because the questions posed to reviewers in the rubric are pointed and specific, they tend to elicit feedback that is strictly focused on the journal's interests and the reviewers' training. This process facilitates editorial decision making and author revision.

\section{INSTITUTIONAL RESOURCES}

The budget for the journal almost entirely depends on publication costs. At present, Clocks\&Clouds is published online and in print. Editors and administrators feel strongly that using both formats enhances the impact of the journal. Hardcopies of the journal are particularly useful for display purposes, such as in recruiting new authors and reviewers, enticing potential students, and retaining talent within the university. ${ }^{9}$

Clocks\&Clouds published its first two volumes in twice-yearly issues but currently is changing to an annual schedule. The number of pages-and therefore printing costs-remains the same, with from 100 to 150 copies of each volume printed, for a total of about 200 pages. ${ }^{10}$ Annual costs are approximately $\$ 3,000$, including printing, advertising, and release and recruitment receptions. Hardcopy publishing comprises $75 \%$ of the journal's costs. It cannot be overemphasized, however, that printing costs are entirely scalable: a journal may print as many copies as possible dependent on resources. However, a small number of "show copies" may be printed or the decision may be to completely forego print publication. Although print copies are potentially useful for display and gratifying for the staff and authors, the benefits of an undergraduate student research journal do not depend on journal format. Online forms and digital displays can accomplish the same goals. Programs that want to initiate their own journal need not be inhibited by lack of funds on this scale.

The funds to operate Clocks\&Clouds reflect the common pattern noted by Mariani et al. (2013) of journals that combine institutional and student-organization revenue streams. The diversity of revenue sources for Clocks\&Clouds not only enhances the pool from which the journal can draw but also multiplies the numbers of actors and interests involved and the relationships that must be managed and maintained.

\section{INSTITUTIONALIZING THE JOURNAL}

A key focus of the efforts of the faculty, administration, and editorial team-not addressed in the scholarship on undergraduate research journals-is the need to institutionalize the journal. This challenge is exacerbated by the turnover of student leaders and partner organizations. This "Achilles' heel" was a concern identified by previous student leadership positions held by the staff of ClocksEClouds. In this case, once the structure, training, and review process were established, efforts shifted to linking the journal to other organizations and offices on campus.

All journals need name recognition on campus, venues for soliciting submissions and recruiting staff, and a means for sustainability over time. Successive editorial teams in Clocks $\mathcal{E}$ Clouds have undertaken to build relationships across campus with staff in various offices and with faculty and students. Included in these relationships are the Honors Program, University Library, Provost's Office, Merit Awards Office, and Student Writing Center, among others. In fact, one former leadership team commented that human support was more important than financial support, meaning that they sought assistance from organizations other than those that funded them and that help came from unexpected sources. By linking disparate campus resources for undergraduate research, the relevance and credibility of a journal is strengthened.

In the second year of Clocks\&Cloud's existence, the editorial staff and faculty advisors also undertook to codify their practices by creating a manual for its functioning. Establishing a full written record of the journal not only eased the transition from one leadership team to the next but also allowed for greater transparency and reflection on these practices. Great care was given to identifying and explaining the institutional relationships and resources, which allowed the culmination of one staff's work to serve as the foundation for the next.

An unanticipated challenge has been in developing a marketing plan. University faculty comprise the most important marketing source for ClocksEClouds, referring students with high-quality papers to the journal and making recommendations for reviewers and staff. However, the journal staff works diligently to connect directly with students across the university. The staff evolved a scheme that uses combinations of social media and campus resources to generate interest in the organization, taking a mixed-media approach to reaching students. The challenge of marketing the journal is a pedagogical opportunity for students with marketing and business interests, resulting in the journal diversifying its staff.

\section{CONCLUSION}

Although in recent years only about 20 political science programs have published journals in the United States, undergraduate research journals have garnered attention and been successful in other fields. Their merits as a pedagogical tool for fostering engagement and knowledge acquisition and application are well known, and many political science programs are discussing the process for creating a similar journal. This article is an in-depth examination of the structure and organization of ClocksEClouds that describes the choices made by the organization's leadership to address key challenges in student-led extracurricular academic activities. The case study provides a guide for resolving these key challenges with relatively minor impact on academic programming or institutional financial resources and with less faculty commitment than other models. The purpose of this study is to encourage other undergraduate programs in political science to form student research publications and to expand the reach of this high-impact educational practice.

\section{NOTES}

1. This number is from our own research in October 2013, which used APSA resources, Google searches, and follow-up e-mails to multiple departments to solicit further information.

2. The Council on Undergraduate Research offers only a list of active journals (see http://www.cur.org/resources/students/undergraduate_journals).

3. American University is a private, doctoral-granting institution with approximately 6,8 oo undergraduates. The two schools, SPA and SIS, graduate approximately 700 students per year. 
4. Applications submitted by students who apply to be reviewers describe their coursework and experiences. As undergraduates, they typically are not "experts" in any subject; however, if a submission exceeds their familiarity, we encourage them to seek assistance from expert faculty if they have questions about the state of the scholarship or the methods in use.

5. Although Clocks\&Clouds originally used a fixed submission date, the most recent leadership team introduced rolling submissions and a staggered reviewer schedule, which allows reviewers to focus on one submission at a time. Thus far, this system has proven more manageable for the staff and reviewers.

6. No papers are accepted outright and almost none are accepted after the initial review process; almost all involve revisions. The review process also is not intended to be terminal; ClocksEClouds attempts to create a healthy attitude about revision, and the staff is willing to work with an article's author through multiple iterations until it is publishable.

7. Clocks\&Clouds now uses anonymous "shell e-mail" accounts so that the staff and the authors can communicate directly with one another while maintaining anonymity. During the "revise and resubmit" period, this allows reviewers to explain their suggestions to authors or vice versa if questions arise.

8. Whereas some journals contract out copyediting and design, the leadership of Clocks\&Clouds believes that giving interested students the opportunity to contribute to the journal in this way provides valuable, career-relevant experience; it is one of the journal's key "deliverables" to the staff.

9. Materials referenced in this article are available free of charge on the official Clocks\&Clouds web page at http://edspace.american.edu/clocksandclouds.

10. ClocksfClouds does not make publication decisions based on financial considerations. If too many articles of publishable quality are submitted, the staff delays their publication to a subsequent issue. Approximately $20 \%$ of all articles published are in this category.

\section{REFERENCES}

Bauer, Benjamin J., Whitney C. Ogas, Omar M. Shakir, Zoe M. Oxley, and Rosalee A. Clawson. 2009. "Learning through Publishing: The Pi Sigma Alpha Undergraduate Journal of Politics." PS: Political Science \& Politics 42 (3): 565-9.

Charlesworth, Susanne M., and Ian D. L. Foster. 1996. "Water and Environmental Systems: Achieving Student-Centered Learning Objectives with an Undergraduate Journal." Journal of Geography in Higher Education 20 (1): 45-54.

Kuh, George D. 2008. High-Impact Educational Practices: A BriefOverview. Washington, DC: Association of American Colleges \& Universities.

Mariani, Mack, Buckley Fiona, Reidy Theresa and Richard Witmer. 2013. "Promoting Student Learning and Scholarship through Undergraduate Research Journals." PS: Political Science and Politics 46 (4): 830-5.

Osborn, Jeffrey M., and Kerry K. Karukstis. 2009. "The Benefits of Undergraduate Research and Creative Activity." In In Broadening Participation in Undergraduate Research: Fostering Excellence and Enhancing the Impact, ed. K. Boyd Mary, and Jody L. Wesemann, 41-53. Washington, DC: Council on Undergraduate Research.

Russell, Susan H., Mary P. Hancock, and James McCullough. 2007. "Benefits of Undergraduate Research Experiences." Science 316: 548-9.

Smith, Pliny A., Shaun Davis, Michael Fiske, and Shubhik DebBurman. 2009 "Eukaryon: The Use of an Undergraduate Scholarship Journal to Strengthen Inquiry-Based Pedagogy and a Community of Undergraduate Scholars." Developmental Biology 331: 415.

Stallings, Dr. Virginia. 2014. Vice-Provost for Undergraduate Studies, personal interview by Kimberly Cowell-Meyers, March 6.

Watcke, Ronald R., and Patricia Winterfield. 1979. "The Sociologist as Editor: Motor City Review: A Sociology Journal of Student Research.” Teaching Sociology $6(4): 420-8$. 